\title{
HtrA1-dependent proteolysis of TGF- $\beta$ controls both neuronal maturation and developmental survival
}

\author{
S Launay ${ }^{1}$, E Maubert ${ }^{1}, \mathrm{~N}$ Lebeurrier ${ }^{1}$, A Tennstaedt ${ }^{2}$, M Campioni ${ }^{3}$, F Docagne ${ }^{1}$, C Gabriel ${ }^{1}$, L Dauphinot ${ }^{4}$, MC Potier $^{4}$, M Ehrmann $^{2}$, \\ $A$ Baldi ${ }^{3}$ and D Vivien ${ }^{*, 1}$
}

Transforming growth factor- $\beta$ (TGF- $\beta$ ) signalling controls a number of cerebral functions and dysfunctions including synaptogenesis, amyloid- $\beta$ accumulation, apoptosis and excitotoxicity. Using cultured cortical neurons prepared from either wild type or transgenic mice overexpressing a TGF- $\beta$-responsive luciferase reporter gene (SBE-Luc), we demonstrated a progressive loss of TGF- $\beta$ signalling during neuronal maturation and survival. Moreover, we showed that neurons exhibit increasing amounts of the serine protease HtrA1 (high temperature responsive antigen 1) and corresponding cleavage products during both in vitro neuronal maturation and brain development. In parallel of its ability to promote degradation of TGF- $\beta 1$, we demonstrated that blockage of the proteolytic activity of HtrA1 leads to a restoration of TGF- $\beta$ signalling, subsequent overexpression of the serpin type -1 plasminogen activator inhibitor (PAl-1) and neuronal death. Altogether, we propose that the balance between HtrA1 and TGF- $\beta$ could be one of the critical events controlling both neuronal maturation and developmental survival.

Cell Death and Differentiation (2008) 15, 1408-1416; doi:10.1038/cdd.2008.82; published online 13 June 2008

Transforming growth factor- $\beta$ controls a plethora of neuronal and glial functions throughout life, under normal or pathological conditions including the functional neuronal connectivity, ${ }^{1}$ apoptotic pathways, ${ }^{2,3}$ glutamatergic signalling ${ }^{4}$ and amyloid$\beta$ turnover. ${ }^{5}$ TGF- $\beta$ isoforms elicit their cell type-specific responses through the ligand-induced formation of a heteromeric receptor complex between the serine/threonine kinases $\mathrm{T} \beta \mathrm{R}-\mathrm{I}$ and $\mathrm{T} \beta \mathrm{R}-\mathrm{II}$ : the type II receptor binds TGF- $\beta$ by its own, then recruits the type I receptor, allowing the transphosphorylation-mediated activation of $\mathrm{T} \beta \mathrm{R}-\mathrm{I}$. The subsequent activation of the Smad (signalling mother against decapentaplegic peptide) transcription factor cascade thus regulates the transcription of key target genes. ${ }^{6}$ Historically, Smads were thought to be the main substrates and the key signal transducers of activated TGF- $\beta$ receptors. However, an ever increasing complexity in the canonical TGF- $\beta$ intracellular cascade emerges, with the discovery of cross-talks with other signalling pathways such as mitogen-activated protein kinases or Wnt and the description of multiple regulatory factors, including Ski and SnoN or processes such as ubiquitination. ${ }^{1,7}$

The bacterial serine-protease HtrA, also known as DegP, is a heat shock-induced envelope-associated serine protease. ${ }^{8}$ Its main role is to recognize and degrade misfolded proteins in the periplasm, combining a dual activity of chaperone and protease. ${ }^{9}$ Four human homologues of HtrA have been identified and named respectively human HtrA1 (PRSS11 or L56), ${ }^{10} \mathrm{HtrA} 2$ (Omi), ${ }^{11} \mathrm{HtrA} 3$ (PRSP) and HtrA4. HtrA2 is localized at the mitochondrial membrane and is involved in apoptosis. ${ }^{12} \mathrm{HtrA} 1, \mathrm{HtrA} 3$ and $\mathrm{HtrA} 4$ are secreted proteases. Ubiquitously expressed in normal human adult tissues, ${ }^{13}$ HtrA1 contains in addition to a highly conserved protease domain (trypsin like serine protease domain), an insulin growth factor-binding domain, a kazal type $\mathrm{S}$ protease inhibitor domain followed by one or two post-synaptic disclarge zona domains and a follistatin-like domain. ${ }^{10}$ There is increasing evidences that HtrA1 regulates several physiological and pathological processes including tumour development, ${ }^{14}$ Alzheimer's disease (AD), ${ }^{15}$ placentation, ${ }^{16}$ age-related macular degeneration ${ }^{17}$ and osteoarthritis. ${ }^{10} \mathrm{How}$ ever, the mechanism(s) by which it regulates these processes has(ve) not been fully elucidated. Considering its subcellular distribution, either found as a secreted protein or in the cytoplasm of the cells, ${ }^{16} \mathrm{HtrA} 1$ could act on different targets including extra-cellular matrix proteins. Interestingly, both $\mathrm{HtrA} 1$ and $\mathrm{HtrA} 3$ isoforms have been reported to inhibit TGF- $\beta$ signalling during development ${ }^{18,19}$ through a proteolyticallydependent interaction with ligands of the TGF- $\beta$ family. In parallel, the analysis of HtrA1 protein sequence has revealed that the amino-terminal region of human HtrA1 is closely related to mac25, a putative growth suppressor considered to act as an activated follistatin. ${ }^{20}$ It is well known that follistatin plays an important role in the negative regulation of TGF- $\beta$ family members such as BMP4, Gdf5, TGF- $\beta$ s and activin, glycoproteins belonging to the TGF- $\beta$ superfamily. ${ }^{21}$

${ }^{1}$ INSERM, INSERM U919, Serine Proteases and Pathophysiology of the neurovascular Unit (SP2U), UMR CNRS 6232 Ci-NAPs 'Center for imaging Neurosciences and Applications to Pathologies', Cyceron, University of Caen Basse-Normandie, Caen Cedex F-14074, France; 'Zentrum für Medizinische Biotechnologie, University of Duisburg-Essen, Universitätsstraße, Essen 45117, Germany; ${ }^{3}$ Department of Biochemistry, Section of Pathology, Second University of Naples, Naples 8010 , Italy and ${ }^{4}$ Neurobiologie et Diversité Cellulaire CNRS UMR7637 ESPCI 10 rue Vauquelin, Paris 75005, France

${ }^{*}$ Corresponding author: D Vivien, INSERM U919, Serine Proteases and Pathophysiology of the Neurovascular Unit (SP2U), UMR CNRS 6232 Ci-NAPs 'Center for imaging Neurosciences and Applications to Pathologies', Cyceron, Bd H. Becquerel, BP 5229, Caen Cedex 14074, France.

Tel: + 33231470166; Fax: + 33231470222; E-mail: vivien@ cyceron.fr

Keywords: HtrA1; neuronal survival; PAI-1; TGF- $\beta$ signalling; tPA

Abbreviations: HtrA, high temperature responsive antigen

Received 21.1.08; revised 17.4.08; accepted 15.5.08; Edited by N Bazan; published online 13.6.08 
In the present study, we hypothesized that the serine protease HtrA1 could play a critical role in controlling TGF- $\beta$ dependent neuronal signalling and neuronal survival.

\section{Results}

A loss of TGF- $\beta$ signalling occurs with in vitro neuronal maturation. mRNA levels for NMDA receptor subunits, synaptophysin, synapsin and PSD95 (post synaptic density protein of $95 \mathrm{kDa}$ ) were studied in primary cultures of cortical neurons maintained from 2 to 14 days in vitro (DIV). With DIV, cultured neurons showed increased levels of mRNAs encoding for NMDA receptor subunits 1, 2A, 2B, 2D (Figure 1a), for synapsin, synaptophysin and PSD95 (Figure $1 \mathrm{~b}$ ), all previously characterized ${ }^{22,23}$ as markers of neuronal differentiation and functionality. Then, TGF- $\beta$ signalling was investigated in sister cultures obtained as described in the methods section, from transgenic mice overexpressing the previously described luciferase reporter gene under the control of the TGF- $\beta$-specific Smad-binding element (SBE), CAGA box ${ }^{24}$ and maintained 2, 5, 7 and 14 DIV. Both cultured neurons and astrocytes were treated in the presence of recombinant TGF- $\beta 1$ ( $1 \mathrm{ng} / \mathrm{ml}, 24 \mathrm{~h})$ and luciferase reporter activity measured. Although primary cultured astrocytes are responsive to TGF- $\beta$ whatever the duration of in vitro maturation studied (up to fivefold induction) (Figure 2a), neurons lose their responsiveness to
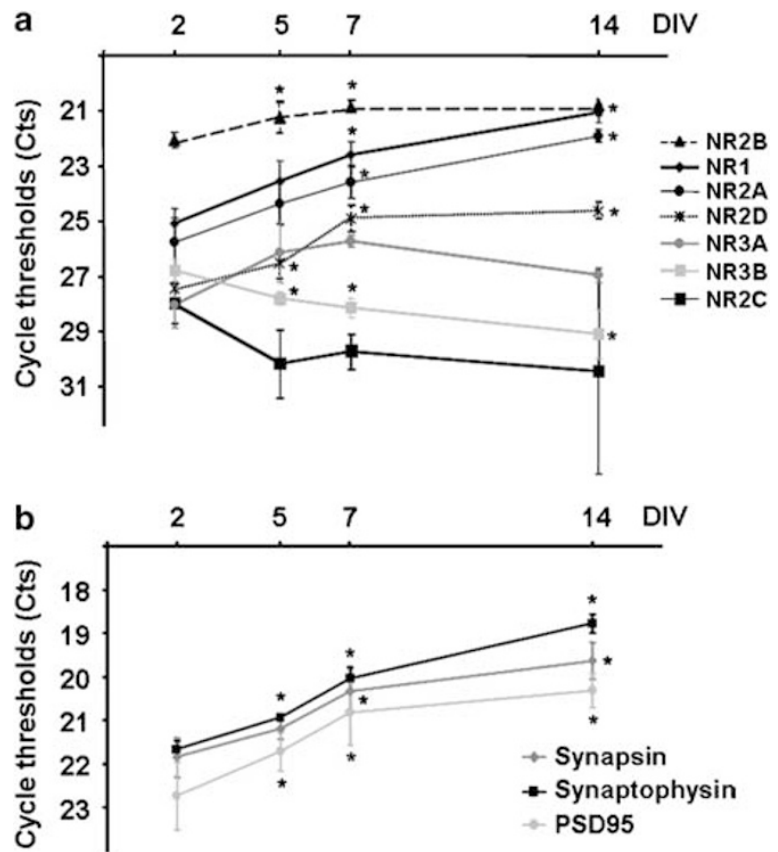

Figure 1 Increased expression of a set of neuronal markers with maturation. (a) mRNA levels of NMDA receptor subunits (NR1 to NR3B) in cultured neurons at 2, 5, 7 and $14 \operatorname{DIV}(N=3, n=9)$. (b) mRNA levels for postsynaptic markers (Synapsin Synaptophysin, PSD95) in cultured neurons at 2, 5, 7 and 14 DIV $(N=3, n=9)$. Relative levels of mRNA expression were measured by quantitative PCR. Results were computed in Cycle thresholds $\left(C_{\mathrm{ts}}\right)$. Points represent mean values \pm S.D. ${ }^{*}$ Indicates significantly different from the 2 DIV value $\left({ }^{*} P<0.05\right)$ by one way Kruskall-Wallis test followed by Mann-Whitney post hoc test
TGF- $\beta$ between 5 and 7 days in vitro (Figure 2b). This effect is maintained at least until 14 DIV. To note, immunoblotting performed against the astrocytic marker (glial fibrillaric acidic protein) shows that our primary cultures of neurons are not contaminated with significant amounts of astrocytes (Figure 2c), demonstrating the neuronal specificity of the results obtained. As TGF- $\beta$ signalling was previously demonstrated to control the expression of the serpin plasminogen activator inhibitor (PAI-1), ${ }^{4}$ mRNA levels for $\mathrm{PAl}-1$ were determined in control conditions at the different stages in vitro by using quantitative RT-PCR. As previously reported, ${ }^{25}$ whatever in vitro stage, astrocytes exhibit high levels of mRNA encoding for PAl-1 (data not shown). In contrast (Figure $3 a$ ), although neurons maintained 2 days in vitro display high levels of mRNA for PAl-1, this expression is dramatically decreased with days in vitro with a reduction of up to $50 \%$ between 5-14 DIV. In parallel, the expression of the other serpins related to tPA, neuroserpin and protease nexin 1 (PN1, slight increase) and the expression of tPA failed to be influenced by the stage of in vitro development (Figure 3a). In addition, establishing the link between TGF- $\beta$ signalling and PAl-1 mRNA levels, our data show that PAl-1
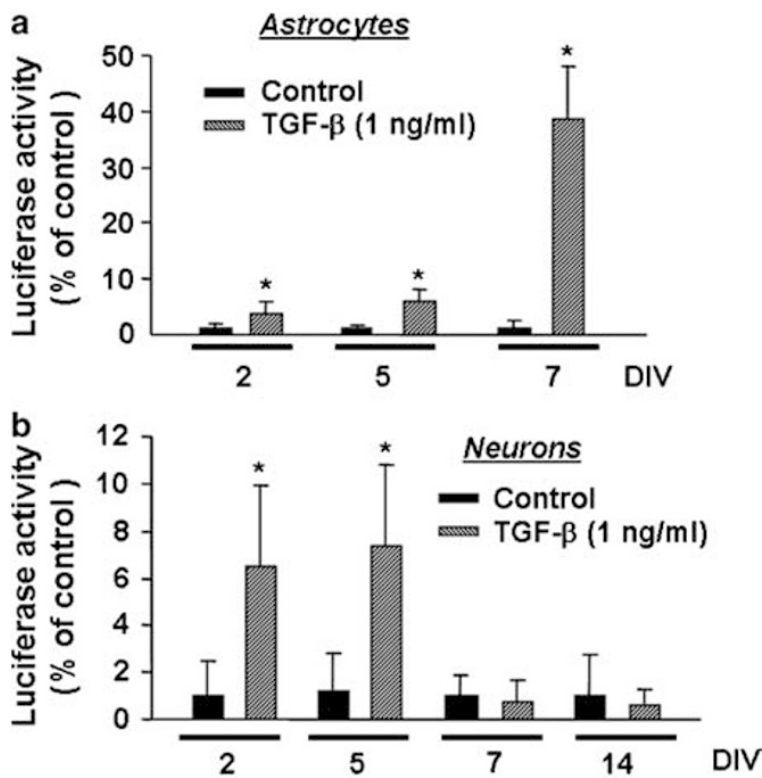

c

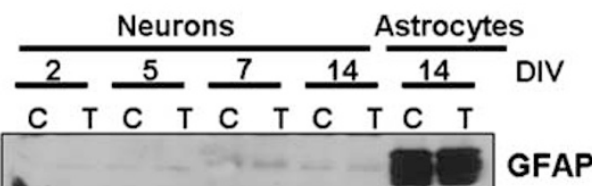

Figure 2 Neurons lose their responsiveness to TGF- $\beta$. (a and $\mathbf{b}$ ) Cultured neurons and astrocytes obtained from SBE-luc transgenic mice displaying a luciferase reporter gene under the control of a Smad binding element: $\mathrm{SBE}^{24}$ were treated at 2, 5, $7(n=12)$ and 14 DIV $(n=4)$ for neurons and 2, 5 and 7 DIV $(n=6)$ for astrocytes in the presence of TGF- $\beta 1$ at $1 \mathrm{ng} / \mathrm{ml}$ for $24 \mathrm{~h}$. Luciferase activity from cell lysates was quantified by luminescence (mean \pm S.D.) using the luciferase system kit, as described by the manufacturer. *Indicates significantly different from control $\left({ }^{*} P<0.05\right)$ by one way Kruskall-Wallis test followed by Mann-Whitney post hoc test. (c) Neurons at 2, 5, 7 and 14 DIV and astrocytes at 14 DIV were treated or not in the presence of TGF- $\beta 1$ at $1 \mathrm{ng} / \mathrm{ml}$ for $24 \mathrm{~h}$. Immunoblots were revealed with an antibody raised against mouse GFAP $(N=3)$ 

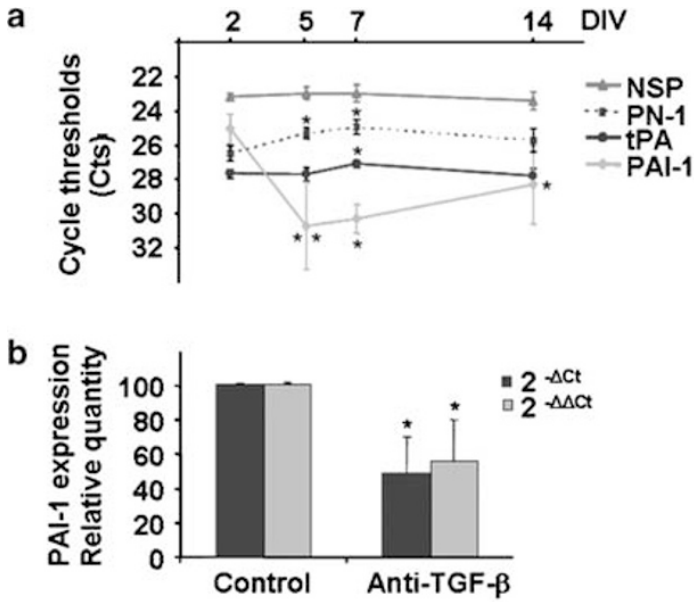

c Zymography assay

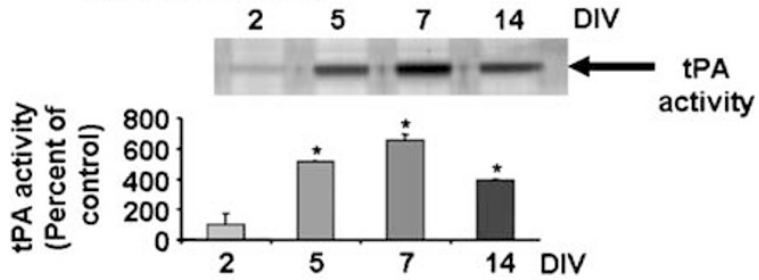

d Fluorogenic substrate

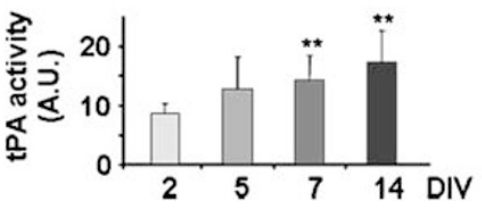

Figure 3 Neurons lose PAI-1 expression with DIV. (a) Evaluation of tPA and its serpins (protease nexine 1 (PN-1), plasminogen activator inhibitor (PAl-1) and neuroserpin (NSP)) mRNA levels during neuronal in vitro maturation $(N=6$, $n=18$ ). Relative levels of mRNA expression were measured by quantitative PCR. Points represent mean values \pm S.D. *Indicates significantly different from the 2 DIV value $\left({ }^{*} P<0.05,{ }^{* *} P<0.01\right)$. (b) Evaluation by real time PCR of the mRNA levels for PAl- 1 in cultured neurons treated at 2 DIV with a blocking antibody raised against TGF- $\beta$ at $5 \mu \mathrm{g} / \mathrm{ml}$ for $48 \mathrm{~h}$ (Pan-specific TGF- $\beta$ antibody, R\&D Systems). Results were computed with the two following formulas: black bars represent $2^{-\Delta C t}(=$ $\left.2^{-(\Delta C \text { t of PAl }-1)}\right)$ and grey bars represent $2^{-\Delta \Delta C}\left(=2^{-(\Delta C \text { t of PAl }-1-\Delta C \text { t of cyclophilin })}\right)$. Bars represent mean values \pm S.D. *Indicates significantly different from control value $\left({ }^{*} P<0.05\right)$ by one way Kruskall-Wallis test followed by Mann-Whitney post hoc test. (c) Zymography analysis of IPA proteolytic activity was performed on proteins extracted from cultured neurons at 2, 5, 7 and 14 DIV old with densitometric analysis. Data are represented as mean \pm S.D. $(N=3)$ relative to 2 DIV cultured neurons; ( ${ }^{*} P<0.05$ ); Kruskall-Wallis test followed by Mann-Whitney post hoc test. (d) IPA activity is increased with DIV. IPA activity was measured by using a fluorogenic substrate (XF444) on medium obtained from cultured neurons at 2, 5, 7 and 14 DIV old. Data are represented as mean \pm S.D. $(N=3, n=6)$ relative to 2 DIV cultured neurons $\left({ }^{*} P<0.05\right)$

expression is significantly reduced by a $48 \mathrm{~h}$ treatment of 2 DIV cultured neurons in the presence of a previously characterized blocking antibody raised against TGF- $\beta$ (Figure $3 b$ ). Then, the endogenous proteolytic activity of tPA contained either in the neuronal monolayer (Figure 3c) or in corresponding bathing media (Figure 3d) was measured as described in the Materials and methods section. We show that lowering of PAI-1 expression is, as expected, associated with an enhanced proteolytic activity of tPA.
Upregulation of the expression of the serine protease, HtrA1, occurs both during in vitro neuronal maturation and in vivo brain development. Microarray analyses comparing gene expression in primary cultures of neurons maintained for 2 versus 15 DIV revealed that among around 10000 genes analyzed, the expression of some of them was significantly influenced by the stage of in vitro maturation (See GEO database under the accession number GSE11162). Interestingly, while selecting serine proteases as a keyword for analyzing the microarray data, we found that the high temperature responsive antigen 1 ( $\mathrm{HtrA} 1$ or PRSS11) gene was upregulated with DIV. This was then confirmed by quantitative PCR in human and murine neuronal cultures.

Thus, we have postulated that an overexpression of the previously characterized antagonist of TGF- $\beta$ signalling, HtrA1, could control the loss of neuronal TGF- $\beta$ signalling observed with days in vitro. By using quantitative RT-PCR, although mRNA expression for both TGF- $\beta$ receptors (T $\beta$ R-I and $T \beta R-I I)$ were not modulated (data not shown), overexpression of HtrA1 was confirmed in primary cultures of cortical neurons from mice (Figure 4a) with an upregulation of its expression with days in vitro (up to twofold increase). Quantitative RT-PCR performed in parallel from mRNA harvested in primary cultures of mouse cortical neurons at 2, 5, 7 and 14 DIV revealed no modification of the expression of HtrA2, 3 and 4 (Figure 4a). Neuronal overexpression of HtrA1 with days in vitro was also confirmed at the protein level by immunoblotting performed from the cell monolayer revealed with an antibody raised against HtrA1 (Figure 4b). Immunoblotting showed an enhanced positive processing/ cleavage of HtrA1 with days in vitro. Parallel experiments were performed in vivo. mRNA levels for both HtrA1 and PAI-1 were measured from brain cortex of mice at different stages of development (E16 to adults). As shown in vitro, we can observe a dramatic increase of the mRNA levels encoding for HtrA1 in animals from E20 to adults (Figure 4c), with an associated decrease in the mRNA levels encoding for PAI-1 (Figure 4d). It is interesting to note, that the overexpression of HtrA1 appeared before the decrease of PAI-1 (E20 versus P1). Similarly, immunoblotting raised against HtrA1 revealed an increased level of HtrA1 associated with an increased processing/cleavage of the protein HtrA1 during brain development (Figure 4e). Immunohistochemistry performed in animals from E16 to P1 showed positive staining for HtrA1 during brain development in neurogenic areas including the ventricular zones (Figure $5 \mathrm{a}-\mathrm{C}$ ). In adult brains, positive immunostainings for HtrA1 were observed mainly in cortical areas both in glial cells (GFAP stained; Figure $5 \mathrm{~h}$ ) and neurons (either $\beta$-III tubulin (Tuj 1) or NeuN-stained; Figure $5 \mathrm{e}-\mathrm{g}$ ). Neuronal HtrA1 immunostainings displayed mainly a membrane-associated labelling.

HtrA1 controls neuronal TGF- $\beta$ signalling and subsequent neuronal survival. To further investigate the relationship between TGF- $\beta$ and HtrA1 and their ability to control the expression of the serpin PAl-1 in neurons, primary cultures of cortical neurons were treated with the previously characterized HtrA1 inhibitor, NVP-LBG976. After 2 days of treatment, the reduction of PAl-1 expression (mRNA) 



Figure 4 Expression of HtrA members and PAI-1 with neuronal maturation and in vivo brain development. (a) Evaluation by real time PCR of the mRNA levels for HtrA1, $\mathrm{HtrA}$ 2, HtrA3 and HtrA4 in cultured neurons at 2, 5, 7 and $14 \mathrm{DIV}(N=3, n=9)$. Results were computed in $C_{\mathrm{ts}}$. Points represent mean values \pm S.D. *Indicates significantly different from the 2 DIV value $\left({ }^{*} P<0.05\right)$; Kruskall-Wallis test followed by Mann-Whitney post hoc test. (b) Immunoblot raised against HtrA1 was performed on proteins extracted from cultured neurons at 2, 5, 7 and 14 DIV old $(N=4)$. (c and d) Evaluation by real time PCR of the mRNA levels for HtrA1 and PAI- 1 in cerebral cortex of Swiss mice from $\mathrm{E} 16$ to adults $(\mathrm{E} 16 N=6, \mathrm{E} 20 N=3, \mathrm{P} 1 \mathrm{~N}=6, \mathrm{P} 3 N=6, \mathrm{P} 7 \mathrm{~N}=6$ and adults $N=4)$. Results were computed in $C_{\text {ts. }}$. Points represent mean values \pm S.D. ${ }^{*}$ Indicates significantly different from the $\mathrm{E} 16$ value $\left({ }^{\star} P<0.05,{ }^{\star \star} P<0.01\right)$; Kruskall-Wallis test followed by Mann-Whitney post hoc test. (e) Immunoblot raised against HtrA1 was performed on proteins extracted from cerebral cortex of Swiss mice from E16 to adults $(N=3)$

previously observed with days in vitro was restored. Indeed, although PAI-1 mRNA levels were decreased with DIV in control neurons, blockage of the proteolytic activity of HtrA1 increased PAI-1 mRNA levels (up to $100 \%$ at $24 \mathrm{~h}$, up to $400 \%$ at $48 \mathrm{~h}$, up to $400 \%$ at $72 \mathrm{~h}$ and up to $200 \%$ at $96 \mathrm{~h}$ (Figure 6a). Accordingly, treatment of neurons with the HtrA1 inhibitor led to an associated decrease of the endogenous proteolytic activity of tPA as estimated by fluorogenic and zymography assays (Figure $6 \mathrm{~b}$ and $c$ respectively). Then, the possible involvement of both $\mathrm{HtrA} 1$ and TGF- $\beta$ signalling in the control of neuronal survival was investigated. Primary cultures of cortical neurons maintained for 2 days in vitro were treated with the HtrA1 inhibitor (NVP-LBG976, $6 \mu \mathrm{M}$ ) for 5 days (from 2 to 7 DIV) prior to estimation of neuronal survival. Blockage of the proteolytic activity of $\mathrm{HtrA} 1$ led to a significant neuronal death, an effect prevented by either the co-application of an anti- TGF- $\beta$ blocking antibody or recombinant IPA while by themselves these treatments did not affect cell survival (Figure 6d). Interestingly, as it was reported that HtrA1 could inhibit TGF- $\beta$ signalling through a proteolytically-dependent interaction, ${ }^{19}$ the ability of purified recombinant $\mathrm{HtrA} 1$ to cleave recombinant TGF- $\beta 1$ was tested (Figure 7). Our data clearly show that co-incubation of proteolytically active $\mathrm{HtrA} 1$ with recombinant TGF- $\beta 1$ leads to a dramatic degradation of the cytokine. Altogether, these data demonstrate that progressive loss of neuronal TGF- $\beta$ signalling is a consequence of an overexpression and proteolytic process of neuronal $\mathrm{HtrA} 1$, an effect leading to a reduced PAl-1 expression, an increased proteolytic activity of tPA and subsequent neuronal survival and maturation (Figure 8).

\section{Discussion}

Although the cytoplasmic HtrA1 was involved in chemotherapy-induced apoptosis, ${ }^{26}$ other reports supposed that HtrA1 could also be secreted and act in the extracellular space. Indeed, HtrA1 has been detected in the synovial fluid of osteoarthritic and rheumatoid arthritic patients ${ }^{27}$ and has been described to be secreted by astrocytes. ${ }^{15}$ Here, we evidence that cultured neurons exhibit both mRNAs and proteins for $\mathrm{HtrA1}$. Moreover, we show that HtrA1 expression is associated with neurogenic areas during brain development and with both glial cells and neurons in the adult brains. Although the mechanisms of HtrA1 actions remain largely unknown, $\mathrm{HtrA} 1$ was reported to inhibit TGF- $\beta$ family signalling. ${ }^{19}$ Indeed, experiments using series of deletion mutants for $\mathrm{HtrA} 1$ have indicated that $\mathrm{Htr} \mathrm{A} 1$ and possibly HtrA3 could bind some TGF- $\beta$ family members such as BMP4, Gdf5, TGF- $\beta$ s and activin ${ }^{18,19}$ leading to a proteolytically dependent 

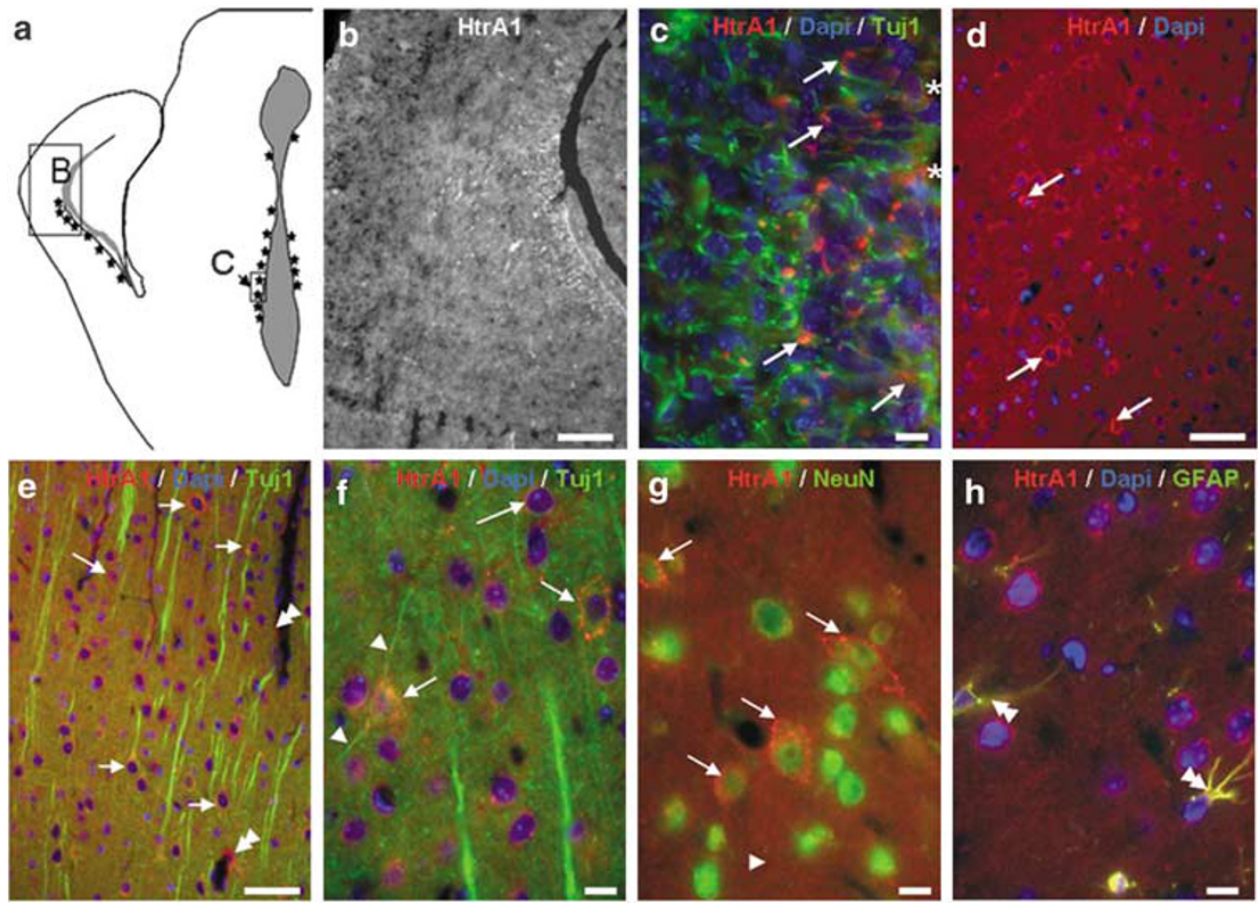

Figure 5 Immunohistochemical detection of HtrA1 in E16 embryo (a-c) or adult cortices (d-h). (a) Schematic view of a coronal section showing neurogenic areas expressing HtrA1 immunoreactivity (stars). At this stage, these areas are characterized by an intense immunostaining for HtrA1 (arrows in b or $\mathbf{c}$ ). At high magnification (d), HtrA1 immunoreactivity reveals large punctuation associated to cells of the ventricular zone (stars show the third ventricle). Coronal sections of adult cortices (d-h) display a large distribution of HtrA1 immunoreactivity. In the adult cortex, HtrA1 immunoreactivity is associated to neuronal cell bodies (arrows in $\mathbf{d}-\mathbf{g}$ ), astrocytes and astrocytic endfeets (double arrowheads in $\mathbf{e}$ and $\mathbf{h}$ ). The neuronal expression of HtrA1 is revealed by double immunostainings in cortical neurons (arrows in e-f) revealed either by Tuj 1 (FITC in $\mathbf{e}$ and $\mathbf{f}$ ) or by NeuN immunoreactivity (FITC in $\mathbf{g}$ ). The astrocytic localization of HtrA1 immunoreactivity is shown in (h) (yellow labeling) in the merged image of a double immunostaining against GFAP (FITC) and HtrA1 (TRITC) in neuronal cell bodies. Scale bars represent $200 \mu \mathrm{m}$ for (b) $50 \mu \mathrm{m}$ for (d, e) and $10 \mu \mathrm{m}$ for (c, f, $\mathbf{g}$ and $\mathbf{h})$

inhibition of TGF- $\beta$-related signalling. Accordingly, we provide here, the demonstration that regulation of the proteolytic activity of endogenous HtrA1-controlled neuronal TGF- $\beta$ signalling. Biological actions of TGF- $\beta$ s are mediated by high affinity serine-threonine kinase receptors (T $\beta R-I$ and $T \beta R-I I)$ and subsequent activation of the Smad-dependent signalling cascade leading to the transcriptional regulation of a set of gene-promoters containing the Smad-binding element (SBE) also named CAGA box. ${ }^{28}$ Using primary cultures of cortical neurons and astrocytes from transgenic mice displaying the SBE-luciferase reported gene, known to reveal cerebral TGF- $\beta$ signalling, ${ }^{24}$ we show that although neurons are responsive to TGF- $\beta$ signalling when maintained for a short period in vitro, they lose TGF- $\beta$ responsiveness with in vitro differentiation/ maturation. These data are in agreement with the low endogenous TGF- $\beta$ signalling observed in adult brains under physiological conditions, a signal dramatically increased following brain injury. ${ }^{29}$ In parallel, our in vivo data show an overprocessing (mRNA and protein levels) of HtrA1 during brain development (E16 to adult brains) associated with a reduced expression of the TGF- $\beta$-dependent regulated serpin, PAI-1. TGF- $\beta$ has been reported to play critical and complex functions and sometimes opposite effects in the central nervous system both during brain development and in the injured adult brains. For example, TGF- $\beta$ s control synaptic growth and neuronal differentiation. Mice with reduced TGF- $\beta 1$ mRNA levels showed an increased susceptibility to age- and excitotoxin-induced brain injury. ${ }^{30}$ During AD, TGF- $\beta$ has been suggested to play critical roles. However, conflicting data have been reported, for instance regarding TGF- $\beta$ levels in $A D$. Indeed, although some authors have found decreased serum levels of the cytokine, ${ }^{31}$ others have reported no difference between $A D$ patients and age-matched controls and no association between serum TGF- $\beta$ levels and AD. ${ }^{32}$ Similarly, although it has been proposed that AD is accompanied by increased TGF- $\beta$ levels within the brain parench$y m a,{ }^{31}$ a recent report suggests that TGF- $\beta$ signalling might be downregulated due to a reduced expression of its $T \beta R$-II receptor. ${ }^{33}$ Similarly, conflicting data have been published regarding the potential role of altered TGF- $\beta$ levels in AD. For instance, in human amyloid precursor protein (hAPP) transgenic mice, a moderate increase in astrocytic expression of TGF- $\beta 1$ was proposed to lead to a reduced $A \beta$ accumulation because of a TGF- $\beta$-dependent phagocytosis of $A \beta$ by microglia. ${ }^{34}$ At the opposite, a deficiency in neuronal TGF- $\beta$ signalling was reported to promote neurodegeneration and Alzheimer's pathology. ${ }^{33}$ Interestingly, HtrA1 was also directly involved in the $\beta$-amyloid pathway, in which HtrA1 colocalizes with $\beta$-amyloid deposits in human brain samples and reduces $\mathrm{A} \beta$ accumulation in astrocytes cell culture supernatants. ${ }^{15}$

In parallel, we have previously demonstrated that TGF- $\beta$ treatment in both murine and human cultured astrocytes leads to an increased transcription of APP and subsequent accumulation of $A \beta .{ }^{5}$ Although brain TGF- $\beta$ levels are highly increased following cerebral ischemia, ${ }^{29}$ TGF- $\beta$ was reported to protect hippocampal, cerebellar and cortical $^{35}$ neurons 


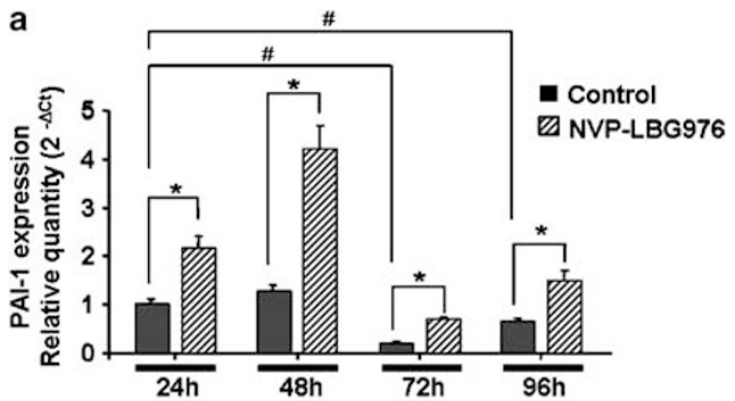

b Fluorogenic assay

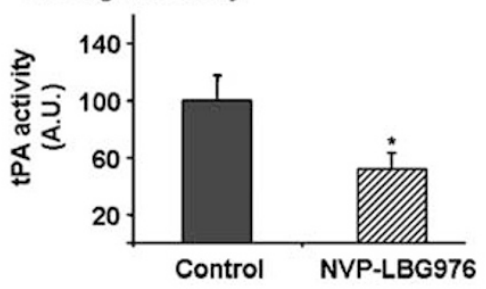

c

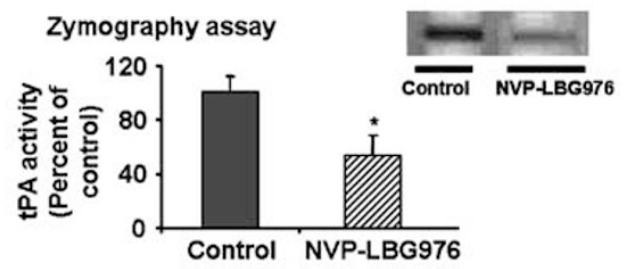

d

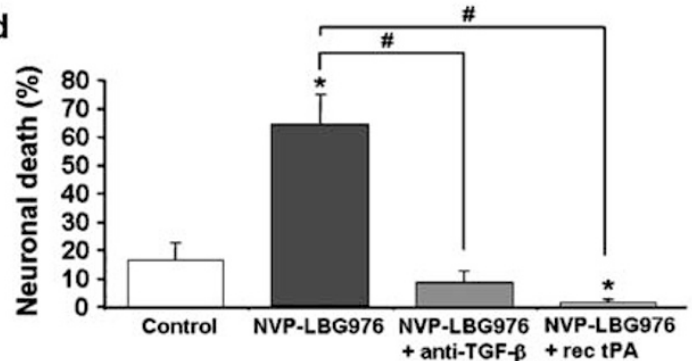

Figure 6 Effect of the HtrA1 inhibitor: NVP-LBG976 on cultured neurons. (a) Evaluation by real time PCR of the mRNA levels for HtrA1 in cultured neurons treated at 2 DIV with NVP-LBG976 $(6 \mu \mathrm{M})$ for $24,48,72$ and $96 \mathrm{~h}(N=3, n=9)$. Data are represented relative to control with the $2^{-\Delta C}$ method. Bars represent mean values \pm S.D. *Indicates significantly different from control and "Indicates significantly different from the $24 \mathrm{~h}$ control $\left({ }^{*} P<0.05,{ }^{\#} P<0.05\right)$; Kruskall-Wallis test followed by Mann-Whitney post hoc test. (b) tPA activity was measured by using a fluorogenic substrate (XF444), from bathing media of cultured neurons at 2 DIV treated or not with NVP-LBG976 $(6 \mu \mathrm{M})$ for $48 \mathrm{~h}$. Data are represented as mean \pm S.D. $(N=3, n=6)$ relative to control. (c) tPA activity is decreased with NVP-LBG976. Zymography assays for the tPA proteolytic activity were performed from protein extracts of cultured neurons at 2 DIV treated or not with NVP-LBG976 $(6 \mu \mathrm{M})$ for $48 \mathrm{~h}$. Data are represented as mean \pm S.D. $(N=3)$ relative to control; $\left({ }^{*} P<0.05\right)$; Kruskall-Wallis test followed by Mann-Whitney post hoc test. (d) Pure cortical neuronal cultures were treated at 2 DIV with NVP-LBG976 $(6 \mu \mathrm{M})$, an antibody raised against TGF- $\beta(5 \mu \mathrm{g} / \mathrm{ml})$ and recombinant tPA $(20 \mu \mathrm{g} / \mathrm{ml})$ for 5 days. At 7 DIV, the percentage of neuronal death was assessed by trypan blue dye staining. Bars represent mean \pm S.E.M. $(N=3, n=9)$. *Indicates significantly different from control $\left({ }^{*} P<0.05\right)$; ${ }^{\#}$ Indicates significantly different from NVPLBG976 ( $\left.{ }^{\#} P<0.05\right)$; Kruskall-Wallis test followed by Mann-Whitney post hoc test

against $\mathrm{N}$-methyl-D-aspartate (NMDA) toxicity. This neuroprotective activity requires the obligatory induction of the synthesis and release of the type 1 plasminogen activator inhibitor (PAI-1) by astrocytes upon activation of TGF- $\beta$

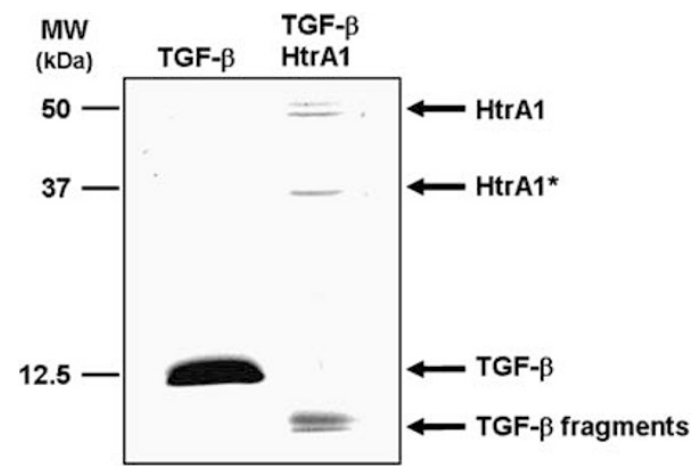

Figure 7 Degradation of TGF- $\beta 1$ by HtrA1. Three micrograms of purified TGF$\beta 1$ were incubated with $0.3 \mu \mathrm{g}$ of $\mathrm{HtrA} 1$ in $50 \mathrm{mM}$ Tris- $\mathrm{HCl} \mathrm{pH} 8$ overnight at $37^{\circ} \mathrm{C}$. As a control, TGF- $\beta$ (lane 1) was incubated separately overnight at $37^{\circ} \mathrm{C}$. Samples were loaded on a SDS/PAGE. The gel was stained with Coomassie Blue. HtrA1* represents autoproteolysis of HtrA1. (Representative of three independent experiments)

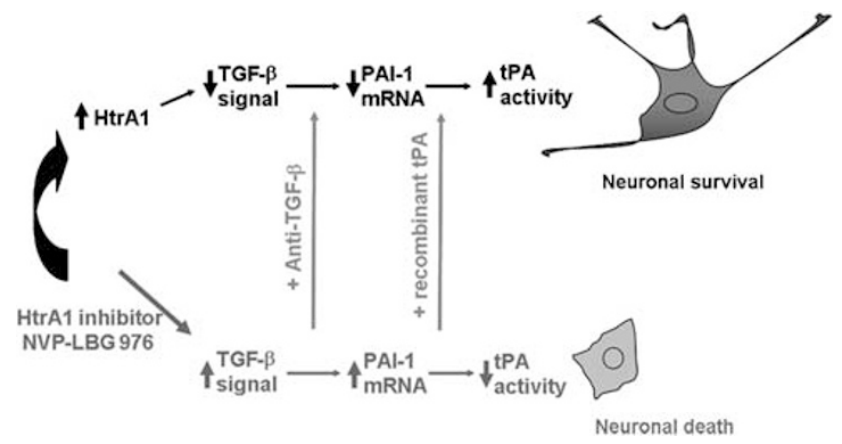

Figure 8 Schematic hypothesis of HtrA1 mechanism of action. We have observed that neurons have lost TGF- $\beta$ response during in vitro differentiation, a phenomenon leading to a reduced expression of the serpin, PAI-1 and subsequent increase of the tPA-dependent proteolytic activity. Interestingly, loss of neuronal TGF- $\beta$ signalling is dependent on the increased expression and proteolytic activity of the serine protease HtrA1. Indeed, an inhibitor of the proteolytic activity of HtrA1 rescues both neuronal TGF- $\beta$ signalling, PAI- 1 expression and reduced IPA activity. In addition, we evidence that loss of neuronal TGF- $\beta$ signalling is critical for neuronal survival. Indeed, neuronal death when initiated in the presence of the $\mathrm{HtrA} 1$ inhibitor is prevented by co-addition of either a blocking antibody for TGF- $\beta$ or recombinant tPA

receptors and through a recruitment of Smad3. ${ }^{4}$ Here, we provide evidence that neurons lose both TGF- $\beta$ signalling and $\mathrm{PAl}-1$ expression with neuronal differentiation, a phenomenon associated to an overexpression of HtrA1. Interestingly, in agreement with previous reports, ${ }^{19}$ we provide in vitro evidence that proteolytically active HtrA1 is capable to mediate proteolysis of TGF- $\beta 1$ as an explanation of its ability to prevent TGF- $\beta$ signalling. In addition, our data demonstrate that an inhibitor of the proteolytic activity of $\mathrm{HtrA} 1$ rescued neuronal expression of PAl-1 in vitro. It has previously been demonstrated that the serine protease, tissue type plasminogen activator (tPA), initially characterized for its capacity to induce fibrinolysis, was also expressed within the cerebral parenchyma to play critical functions including control of memory, learning processes ${ }^{36}$ and excitotoxic neuronal death in the injured brain. ${ }^{37}$ Here, we demonstrate that regulation of neuronal TGF- $\beta$ signalling by HtrA1, controls both PAI-1 
expression and subsequent endogenous tPA proteolytic activity. Interestingly, our present data reveal that the balance between HtrA1 and TGF- $\beta$ signalling is a critical event for the control of neuronal survival. Indeed, blockage of the proteolytic activity of HtrA1 promotes neuronal death, a phenomenon blocked by the co-application of either a blocking antibody for TGF- $\beta$ signalling or addition of recombinant tPA (Figure 6d).

A number of HtrA1 extracellular targets such as the Cpropeptides of fibril-forming types I, II and III procollagen, ${ }^{38}$ fibronectin $^{27}$ and proteoglycans such as aggrecan have been identified to play important functions in extracellular matrix remodeling. Our data evidence that HtrA1 controls neuronal TGF- $\beta$ signalling as a critical event to maintain developmental neuronal survival. HtrA1 could thus be now considered as a 'cytokine-like molecule' of the central nervous system, involved in neuronal maturation during brain development and as a new target for neuroprotection or brain recovery.

\section{Materials and Methods}

Materials. Horse serum, fetal bovine serum and laminin were purchased from Invitrogen. Human rt-PA (Actilyse) was purchased from Boerhinger Ingelheim (Paris, France). The blocking antibody raised against TGF- $\beta$ was purchased from R\&D Systems (Lille, France). $\alpha$-casein was obtained from ICN Biomedicals (Aurore, $\mathrm{OH}, \mathrm{USA}$ ), and human Lys-plasminogen was purchased from Calbiochem. TPA substrate spectrozyme XF-444 was purchased from American Diagnostica (France). HtrA1 inhibitor (NVP-LBG976) was provided by Novartis (Basel, Suisse). All the other chemicals were obtained from Sigma.

Animals. Transgenic mice overexpressing a Smad-binding element luciferase reporter construct (SBE-Luc mice) were provided by T Wyss Coray (Department of neurology and neurological sciences, Stanford, USA). SBE-Luc mice were generated with the SBE-luc plasmid ${ }^{39}$ on a FVB/N or $(\mathrm{SJL} / \mathrm{J} \times \mathrm{C} 57 \mathrm{BL} / 6 \mathrm{~J}) \mathrm{F}_{1}$ genetic background using standard procedures. ${ }^{24}$

Cortical proteins and mRNA extracts were obtained from Swiss mice at different ages including 16- and 20-day-old embryos (E16, E20), 1-, 3- and 7-day-old pups (P1, P3 and P7) and 8-month-old adult mice.

Primary cultures of cortical neurons and astrocytes. Cultured neurons or astrocytes were prepared from mouse embryos (E15-E16) and pups (P1-3) respectively. ${ }^{40}$ Cell suspensions in Dulbecco's modified Eagle's medium (DMEM, Sigma) were seeded on plates coated with $0.1 \mathrm{mg} / \mathrm{ml}$ poly-D-lysine (Sigma) and $0.02 \mathrm{mg} / \mathrm{ml}$ laminin for neurons or $0.1 \mathrm{mg} / \mathrm{ml}$ poly-D-lysine for astrocytes. Cells were cultured in DMEM containing fetal bovine serum, horse serum $(5 \%$ each for neurons and $10 \%$ each for astrocytes) and $2 \mathrm{mM}$ glutamine (Sigma) and maintained at $37^{\circ} \mathrm{C}$ in a humidified $5 \% \mathrm{CO}_{2}$ atmosphere. For neuronal cultures, cytosine $\beta$ arabinoside furanoside (Ara-C, $10 \mu \mathrm{mol} / \mathrm{l}$ ) was added after 3 days in vitro (DIV) to inhibit glial proliferation. Astrocyte cultures were washed every 3 days with phosphate-buffered saline (PBS) to eliminate microglia. Neuronal cultures were used after 2, 5, 7 or 14 days in vitro (DIV).

Reporter gene assay. Cultured neurons and astrocytes were obtained from the SBE-luciferase mice overexpressing a luciferase reporter gene under the control of a Smad-binding element, as described above. Luciferase activities were measured using a commercial luciferase ${ }^{\circledR}$ assay kit (Promega) as described by the manufacturer. Briefly, cultured neurons and astrocytes were treated at different stages of in vitro development with or without TGF- $\beta(1 \mathrm{ng} / \mathrm{ml})$ for $24 \mathrm{~h}$. Treated cells were then exposed to a serum-free medium and luciferase activities were measured $24 \mathrm{~h}$ later.

Extraction of total RNA. Total RNAs were extracted from cultured cells or tissues by using the NucleoSpin ${ }^{\circledR}$ RNA II kit from Macherey-Nagel. The samples were lysed in RA $1^{\mathbb{R}}$ buffer containing $1 \%$ of $\beta$-mercaptoethanol. After filtration of the lysates on Nucleospin filter units, total RNAs were purified on Nucleospin RNA II columns according to the manufacturer's instructions and eluted with RNase-free water.
Microarray analysis. Total RNA were extracted from primary cultures of human neurons maintained 2 and 15 days in vitro. For cultures and mRNA extractions, see Materials and methods described above. The quality of each RNA sample was then checked using the Agilent 2100 Bioanalyzer (Agilent Technologies Inc., Palo Alto, CA, USA). $15 \mu \mathrm{g}$ of total uRNA (Universal Human Reference RNA, Stratagene) and RNA obtained from neurons were converted into CDNA labeled with Cy3 or Cy5. The reverse transcription was performed with random hexamers overnight at $37^{\circ} \mathrm{C}$ in the presence of $10 \mathrm{mM}$ DTT (Invitrogen), 1X First-Strand buffer (Invitrogen), $125 \mu \mathrm{M}$ dNTP, $25 \mu \mathrm{M}$ of fluorescent dye (Amersham) and $400 \mathrm{U}$ of Superscript II (Invitrogen). Labeled cDNAs were then purified using QIAquick PCR purification kit (Qiagen) according to the manufacturer's instructions, and hybridized on HGMP arrays overnight at $42^{\circ} \mathrm{C}$ in $50 \%$ Formamide, $4 \times$ SSC, $0.1 \%$ SDS and $5 \times$ Denhardt's. After hybridization, the scans of HGMP arrays were performed by an Axon 4000B (Axon Instrument) and signal and background intensities were obtained using the GenepixPro 4.1 sofware (Axon Instrument).

Quantitative real-time RT-PCR. One microgram of total RNAs from each sample was reverse-transcribed using the Promega RT system (Promega, Charbonnieres, France; reverse transcription: $42^{\circ} \mathrm{C}$ for $1 \mathrm{~h}$ ). Two primers were designed for each gene using the Beacon Designer software (Bio-Rad, Marnes-laCoquette, France). After design, primer alignments were performed with the Blast database to ensure the specificity of primers. Primer sequences used are available in Supplementary Table 1 (on Cell Death and Differentiation website). PCR solutions were prepared with RNase-free water containing primers and IQ SYBR Green Supermix (Biorad, Marnes-la-Coquette, France).

For PCR amplification, $20 \mu \mathrm{l}$ of mix were added to $5 \mu \mathrm{l}$ of reverse transcription reaction previously diluted (1:20). Two negative controls were performed during each experiment. In the first control, we used samples without reverse transcription as a template to control contamination of RNA with genomic DNA. In the second control, we used RNase-free water instead of CDNA to prove that qPCR mixes were not contaminated with DNA. Assays were run in triplicate on the iCycler iQ real-time PCR detection system (Bio-Rad). The amplification conditions were: Hot Goldstar enzyme activation, $95^{\circ} \mathrm{C}$ for $3 \mathrm{~min} ; 50$ cycles of $\mathrm{PCR}$ at $95^{\circ} \mathrm{C}, 15 \mathrm{~s}$ and $60^{\circ} \mathrm{C}, 1 \mathrm{~min}$. The levels of expression of interest gene were computed as follows: relative mRNA expression $=2^{-(C t \text { of gene of interest) }}$ where $C_{t}$ is the threshold cycle value. Expression of interest gene was also computed with respect to the mRNA expression level of the reference gene transcript using the second formula: relative mRNA expression $=2^{-(\mathrm{Ct} \text { of gene of interest-Ct of gene of reference) }}$

Protein extractions. Cells were lysed on ice in Tris-NaCl-Triton buffer containing $1 \%$ of protease inhibitor cocktail (Sigma) and $1 \%$ of phosphatase inhibitor (Sigma). To clear lysates, samples were centrifuged for $20 \mathrm{~min}(10000 \mathrm{~g})$ at $4^{\circ} \mathrm{C}$. Proteins were quantified by using BCA protein assay (Pierce).

Immunoblotting. Protein samples $(15 \mu \mathrm{l})$ were resolved on a $10 \%$ SDSpolyacryl-amide gel and transferred onto a polyvinylidene difluoride (PVDF) membrane. Membranes were blocked with $5 \%$ dried milk in Tris-buffered saline (TBS) containing $0.05 \%$ Tween 20 and incubated with primary antibodies. After incubation with the corresponding secondary peroxidase-conjugated streptavidine reagent, proteins were visualized with an enhanced chemiluminescence ECL Plus immunoblotting detection system (Perkin Elmer-NEN, Paris, France).

tPA activity measurement. Two techniques were used to evaluate the proteolytic activity of tPA.

(1) Zymography assays were performed according to previously published methods. ${ }^{41}$ Briefly, $15 \mu \mathrm{g}$ of protein extracts were resolved on SDS-PAGE $(12 \%)$ containing casein $(1 \mathrm{mg} / \mathrm{ml})$ and plasminogen $(4.5 \mu \mathrm{g} / \mathrm{ml})$. After migration, the gel was washed in a $2.5 \%$ triton solution and incubated for $3 \mathrm{~h}$ in a buffer containing glycine $(100 \mathrm{mM})$ and EDTA $(10 \mathrm{mM}), \mathrm{pH} 8.3$. Finally, clear bands indicating proteolytic activity were visualized by Coomassie staining.

(2) tPA activity was measured by using a commercial fluorogenic substrate for human tPA (Spectrozyme ${ }^{\circledR}$ XF444). This substrate is a modified peptide corresponding to the cleavage site of tPA (methylsulfonyl-D-phenyl-glycylarginine-7-amino-4-methylcoumarin acetate). Briefly, $50 \mu$ l of conditioned medium were mixed with equal volume of tPA substrate (final concentration: $5 \mu \mathrm{M}$ ). Fluorescence (excitation: 360 , emission: $440 \mathrm{~nm}$ ) was monitored during $120 \mathrm{~min}$ and activity was next estimated by calculating the initial slope of the reaction. Results were expressed in arbitrary units (AU). The substrate was prepared according to manufacturer's instructions. 
Immunohistofluorescence. Deeply anesthetized $(500 \mathrm{mg} / \mathrm{kg}$ of choral hydrate) adult Swiss mice $(n=4)$, were transcardially perfused with cold heparinized saline $(15 \mathrm{ml})$ followed by $150 \mathrm{ml}$ of fixative (sodium phosphate buffer $0.1 \mathrm{M}$. pH 7.4 containing $2 \%$ paraformaldehyde and $0.2 \%$ picric acid). Corresponding brains and embryonic brains $(E 16, n=6)$ were post-fixed or fixed, respectively, by immersion in the same fixative for $18 \mathrm{~h}$. Tissues were frequently rinsed in a veronal buffer containing $20 \%$ sucrose before freezing in Tissue-Tek (Miles Scientific, Naperville, IL, USA). Cryomicrotome-cut transversal sections $(8-12 \mu \mathrm{m})$ were collected on gelatin-coated slides and stored at $-80^{\circ} \mathrm{C}$ before processing.

Series of adjacent sections were immunostained with the rabbit polyclonal antiHtrA1 $\left(1: 800^{13}\right)$, associated, or not, with one of the following primary antibodies: mouse monoclonal anti-NeuN (1:500, Mab377, Chemicon), mouse monoclonal antiGFAP (1:600, Ab-6I, Neomarkers) or mouse monoclonal anti- $\beta$ III tubulin (Tuj 1) conjugated to fluorescein isothiocyanate (FITC) (1:300, ab25770 (TU-20), Abcam) Unstained primary antibodies were visualized with Fab'2 fragments of Donkey antirabbit IgG linked to tetramethyl rhodamine isothiocyanate (TRITC) or Fab'2 fragments of Donkey anti-mouse IgG linked to FITC (both 1:400, Jackson ImmunoResearch, West Grove, USA). Washed sections were coverslipped with antifade medium containing, or not, DAPI and images were digitally captured using a Leica DM6000 microscope-coupled coolsnap camera and visualized with Metavue software (Molecular Devices, USA).

Recombinant production and purification of HtrA1. Purified recombinant $\mathrm{HtrA} 1$ was produced in Escherichia coli and purified by using $\mathrm{Ni}^{2+}$. NTA and ion exchange chromatography as previously described. ${ }^{15}$

Evaluation of neuronal death. Neuronal cultures were treated at 2 DIV with or without NVP-LBG976 (HtrA1 inhibitor) at $6 \mu \mathrm{M}$, in the presence or not of either an antibody raised against TGF- $\beta$ isoforms ( $\beta 1, \beta 1.2, \beta 2, \beta 3$ and $\beta 5)$ at $5 \mu \mathrm{g} / \mathrm{ml}$ or with recombinant tPA at $20 \mu \mathrm{g} / \mathrm{ml}$ for 5 days. Neuronal death was estimated by phasecontrast cell counting after staining with $0.4 \%$ Trypan blue dye. The percentage of neuronal death was estimated as the ratio of Trypan blue-positive neurons to the total number of neurons.

Statistical analysis. Data (mean \pm S.D. and mean \pm S.E.M.) were analyzed by the Kruskall-Wallis test, followed by post hoc comparisons, with the MannWhitney's test.

Acknowledgements. We thank Pr Tony Wyss Coray for providing us the SBE-Luc transgenic mice, Benoit Roussel for his help in microarray data submission and $\mathrm{Dr}$ Carine Ali for her scientific assistance. We are grateful to Novartis for the generous gift of HtrA1 inhibitor: NVP-LBG976. This work was supported by a CIFRE grant from ANRT (National Association for Technical Research) and from Cellial Technologies.

1. Packard M, Mathew D, Budnik V. Wnts and TGF beta in synaptogenesis: old friends signalling at new places. Nat Rev Neurosci 2003; 4: 113-120.

2. Zhu Y, Culmsee C, Klumpp S, Krieglstein J. Neuroprotection by transforming growth factorbeta1 involves activation of nuclear factor-kappaB through phosphatidylinositol-3-OH kinase/Akt and mitogen-activated protein kinase-extracellular-signal regulated kinase1,2 signaling pathways. Neuroscience 2004; 123: 897-906.

3. Zhu Y, Ahlemeyer B, Bauerbach E, Krieglstein J. TGF-beta1 inhibits caspase-3 activation and neuronal apoptosis in rat hippocampal cultures. Neurochem Int 2001; 38: 227-235.

4. Docagne F, Nicole O, Gabriel C. Fernández-Monreal M, Lesné S, Ali C et al. Smad3dependent induction of plasminogen activator inhibitor-1 in astrocytes mediates neuroprotective activity of transforming growth factor-beta 1 against NMDA-induced necrosis. Mol Cell Neurosci 2002; 21: 634-644.

5. Lesné S, Docagne F, Gabriel C, Liot G, Lahiri DK, Buée L et al. Transforming growth factorbeta 1 potentiates amyloid-beta generation in astrocytes and in transgenic mice. $J$ Bio Chem 2003; 278: 18408-18418.

6. Itoh S, ten Dijke P. Negative regulation of TGF-beta receptor/Smad signal transduction Curr Opin Cell Biol 2007; 19: 176-184.

7. Izzi L, Attisano L. Regulation of the TGFbeta signalling pathway by ubiquitin-mediated degradation. Oncogene 2004; 23: 2071-2078.

8. Pallen MJ, Wren BW. The HtrA family of serine proteases. Mol Microbiol 1997; 26 : 209-221.

9. Spiess C, Beil A, Ehrmann M. A temperature-dependent switch from chaperone to protease in a widely conserved heat shock protein. Cell 1999; 97: 339-347.
10. Hu SI, Carozza M, Klein M, Nantermet P, Luk D, Crowl RM. Human HtrA, an evolutionarily conserved serine protease identified as a differentially expressed gene product in osteoarthritic cartilage. J Biol Chem 1998; 273: 34406-34412.

11. Gray CW, Ward RV, Karran E, Turconi S, Rowles A, Viglienghi D et al. Characterization of human $\mathrm{Htr}$ 2, a novel serine protease involved in the mammalian cellular stress response. Eur J Biochem 2000; 267: 5699-5710.

12. Li W, Srinivasula SM, Chai J, Li P, Wu JW, Zhang Z et al. Structural insights into the proapoptotic function of mitochondrial serine protease HtrA2/Omi. Nat Struct Biol 2002; 9: 436-441.

13. De Luca A, De Falco M, Severino A, Campioni M, Santini D, Baldi F et al. Distribution of the serine protease HtrA1 in normal human tissues. J Histochem Cytochem 2003; 51: 1279-1284.

14. Baldi A, De Luca A, Morini M, Battista T, Felsani A, Baldi F et al. The HtrA1 serine protease is down-regulated during human melanoma progression and represses growth of metastatic melanoma cells. Oncogene 2002; 21: 6684-6688.

15. Grau S, Baldi A, Bussani R, Tian X, Stefanescu R, Przybylski M et al. Implications of the serine protease HtrA1 in amyloid precursor protein processing. Proc Natl Acad Sci USA 2005; 102: 6021-6026.

16. De Luca A, De Falco M, Fedele V, Cobellis L, Mastrogiacomo A, Laforgia V et al. The serine protease HtrA1 is upregulated in the human placenta during pregnancy. J Histochem Cytochem 2004; 52: 885-892

17. Yang Z, Camp NJ, Sun H, Tong Z, Gibbs D, Cameron DJ et al. A variant of the HTRA1 gene increases susceptibility to age-related macular degeneration. Science 2006; 314: 992-993.

18. Tocharus J, Tsuchiya A, Kajikawa M, Ueta Y, Oka C, Kawaichi M. Developmentally regulated expression of mouse $\mathrm{HtrA3}$ and its role as an inhibitor of TGF-beta signaling. Dev Growth Differ 2004; 46: 257-274.

19. Oka C, Tsujimoto R, Kajikawa M, Koshiba-Takeuchi K, Ina J, Yano M et al. HtrA1 serine protease inhibits signaling mediated by Tgf beta family proteins. Development 2004; 131 : 041-053.

20. Kato MV, Sato H, Tsukada T, Ikawa $Y$, Aizawa S, Nagayoshi M. A follistatin-like gene, mac25, may act as a growth suppressor of osteosarcoma cells. Oncogene 1996; 12: 1361-1364.

21. Krieglstein K, Strelau J, Schober A, Sullivan A, Unsicker K. TGF-beta and the regulation of neuron survival and death. J Physiol Paris 2002; 96: 25-30.

22. Melloni Jr RH, DeGennaro LJ. Temporal onset of synapsin I gene expression coincides with neuronal differentiation during the development of the nervous system. J Comp Neurol 1994; 342: 449-462.

23. Sans N, Petralia RS, Wang YX, Blahos II J, Hell JW, Wenthold RJ. A developmental change in NMDA receptor-associated proteins at hippocampal synapses. J Neurosci 2000; 20: $1260-1271$

24. Lin AH, Luo J, Mondshein LH, ten Dijke P, Vivien D, Contag CH et al. Global analysis of Smad2/3-dependent TGF-beta signaling in living mice reveals prominent tissue-specific responses to injury. J Immunol 2005; 175: 547-554.

25. Docagne F, Nicole O, Marti HH, MacKenzie ET, Buisson A, Vivien D. Transforming growth factor-beta1 as a regulator of the serpins/t-PA axis in cerebral ischemia. FASEB J 1999; 13: $1315-1324$.

26. Chien J, Aletti G, Baldi A, Catalano V, Muretto P, Keeney GL et al. Serine protease HtrA1 modulates chemotherapy-induced cytotoxicity. J Clin Invest 2006; 116: 1994-2004.

27. Grau S, Richards PJ, Kerr B, Hughes C, Caterson B, Williams AS et al. The role of human HtrA1 in arthritic disease. J Biol Chem 2006; 281: 6124-6129.

28. Massagué J. How cells read TGF-beta signals. Nat Rev Mol Cell Biol 2000; 1: 169-178.

29. Vivien D, Ali C. Transforming growth factor-beta signalling in brain disorders. Cytokine Growth Factor Rev 2006; 17: 121-128.

30. Brionne TC, Tesseur I, Masliah E, Wyss-Coray T. Loss of TGF-beta 1 leads to increased neuronal cell death and microgliosis in mouse brain. Neuron 2003; 40: 1133-1145.

31. De Servi B, La Porta CA, Bontempelli M, Comolli R. Decrease of TGF-beta1 plasma levels and increase of nitric oxide synthase activity in leukocytes as potential biomarkers of Alzheimer's disease. Exp Gerontol 2002; 37: 813-821.

32. Rodríguez-Rodríguez E, Sánchez-Juan P, Mateo I, Llorca J, Infante J, García-Gorostiaga I et al. Serum levels and genetic variation of TGF-beta1 are not associated with Alzheimer's disease. Acta Neurol Scand 2007; 116: 409-412.

33. Tesseur I, Zou K, Esposito L, Bard F, Berber E, Can JV et al. Deficiency in neuronal TGFbeta signaling promotes neurodegeneration and Alzheimer's pathology. J Clin Invest 2006; 116: 3060-3069.

34. Wyss-Coray T, Lin C, Yan F, Yu GQ, Rohde M, McConlogue L et al. TGF-beta1 promotes microglial amyloid-beta clearance and reduces plaque burden in transgenic mice. Nat Med 2001; 7: 612-618.

35. Bruno V, Battaglia G, Casabona G, Copani A, Caciagli F, Nicoletti F. Neuroprotection by glial metabotropic glutamate receptors is mediated by transforming growth factor-beta. J Neurosci 1998; 18: 9594-9600.

36. Seeds NW, Basham ME, Ferguson JE. Absence of tissue plasminogen activator gene or activity impairs mouse cerebellar motor learning. J Neurosci 2003; 23: 7368-7375.

37. Nicole O, Docagne F, Ali C, Margaill I, Carmeliet P, MacKenzie ET et al. The proteolytic activity of tissue-plasminogen activator enhances NMDA receptor-mediated signaling. Nat Med 2001; 7: 59-64. 
38. Murwantoko, Yano M, Ueta Y, Murasaki A, Kanda H, Oka $\mathrm{C}$ et al. Binding of proteins to the PDZ domain regulates proteolytic activity of HtrA1 serine protease. Biochem J 2004; 381 895-904.

39. Dennler S, Itoh S, Vivien D, ten Dijke P, Huet S, Gauthier JM. Direct binding of Smad3 and Smad4 to critical TGF beta-inducible elements in the promoter of human plasminogen activator inhibitor-type 1 gene. EMBO J 1998; 17: 3091-3100.
40. Rose K, Goldberg MP, Choi DW. Cytotoxicity in murine cortical cell culture. In: Tyson CA, Frazier JM (eds) In Vitro Biological Methods. San Diego, California, USA: Academic Press, 1993.

41. Sappino AP, Madani R, Huarte J, Belin D, Kiss JZ, Wohlwend A et al. Extracellular proteolysis in the adult murine brain. J Clin Invest 1993; 92 679-685.

Supplementary Information accompanies the paper on Cell Death and Differentiation website (http://www.nature.com/cdd) 